\title{
April Hath Put a Spirit of Youth in Everything*
}

\author{
Geon Ho Bahn \\ Editor-in-Chief, Korean Academy of Child and Adolescent Psychiatry
}

In 1998, Seri Pak won the U.S. Women's Open with a shot in the hazard. After watching the shot, Seri kids had begun practicing golf and took control of the LPGA after a decade. Following Yuna Kim's gold medal in the 2000 Vancouver Winter Olympic Games, Yuna kids grew up and played great games in PyeongChang. The PyeongChang 2018 Winter Olympic and Paralympic Games have just ended successfully. Sports are drama without a script. This unprecedented drama is both an opportunity for infinite success and an incalculable wound; Team Kim, Garlic Girls' curling of the local city came in second place, winning a silver medal, among the rest of the world; the women speed skaters were in an absurd situation in terms of the teams' preliminary contest. It means that the future cannot be guaranteed. Nevertheless, why do they choose sports? The decision to be a sports player may seem reckless, but perhaps it is a challenging spirit that does not fear failure. After watching the PyeongChang Winter Olympic and Paralympic Games, how will the children perform in next decade?

In the April issue, there are seven articles categorized as three themes. The first theme is about diagnosis. Subin Park has established the reliability and validity of the Korean version of Quantitative Checklist for Autism in Toddlers (QCHAT). Hanik K. Yoo has developed After School Checklist (ASK) for kids with attention-deficit hyperactivity disorder. Genome-wide analysis revealed four novel loci for attentiondeficit hyperactivity disorder in Korean youths by Kukju Kwon. The second theme is the treatment program. Soo Youn Lim examined the effect of a class-based school vio- lence prevention program at the elementary school. Tae-Ho Kim completed a preliminary study on the effectiveness of the peer relationship enhancement program in adoles-cents at risk for Internet and smartphone addiction. Sang-Hyun Kim examined the effect of group cognitive behavior therapy to improve depression and anxiety in adolescents with problematic Internet use. The third theme is the long-term follow-up research on child victims of sexual abuse through the nation-funded sexual violence victim protec-tion center, Seoul Sunflower Children Center, by Soo Young Lee. The papers published in this issue reveal the quality of this journal. The study subjects broadly included children in their infancy to late adolescence. The topics of the research ranged from the development of diag-nostic tools and treatment programs to the follow-up of treatment.

Last year, the Journal of the Korean Academy of Child and Adolescent Psychiatry (JKACAP) published two issues in English and two other issues in Korean. This year, JKACAP is attempting to publish four issues in English. This will increase the burden on the members of the editorial committee and turn into a business that requires great sacrifice and devotion by the people involved. Change is a challenge and challenge can be accompanied by trials and errors. Children like Yuna kids and Seri kids challenge the future with curiosity and enthusiasm regardless of the result or the benefit. As the spring comes, I also have put a spirit of challenge in JKACAP.

*William Shakespeare's Sonnet XCIII. 